ppi $201502 Z U 4645$

Esta publicación cientifica en formato digital es continuidad de la revista impresa ISSN-Versión Impresa 0798-1406 / ISSN-Versión on line 2542-3185Depósito legal pp

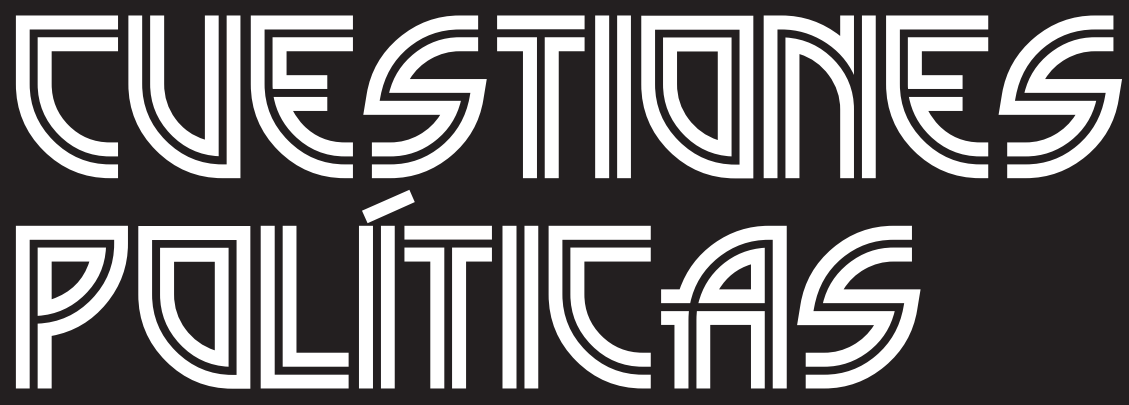

Instituto de Estudios Políticos y Derecho Público "Dr. Humberto J. La Roche' de la Facultad de Ciencias Jurídicas y Políticas de la Universidad del Zulia Maracaibo, Venezuela
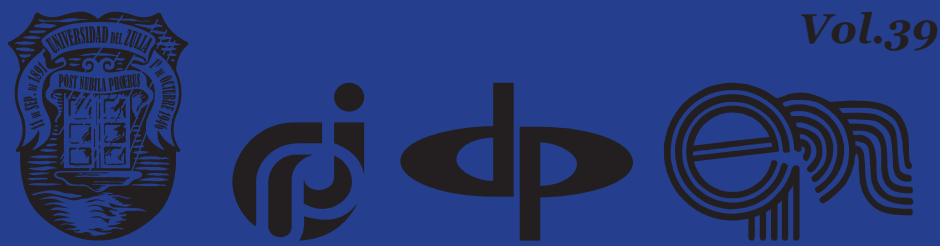


\title{
Inteligencia Artificial: Un Futuro Inteligible
}

\author{
DOI: https://doi.org/10.46398/cuestpol.3968.0o
}

Jorge $F$. Vidovic *

\section{Resumen}

A modo de editorial este ensayo breve tuvo por objetivo reflexionar sobre el presente y futuro próximo de la inteligencia artificial, en el contexto de la pandemia del nuevo coronavirus. Se parte de la hipótesis que observa en la inteligencia artificial un factor de primer orden que ha acelerado los procesos tecnológicos, que a su vez impulsan las mejoras continuas en todos los campos de la acción humana. No obstante, a pesar de sus múltiples beneficios se concluye, por un lado, que esta forma de inteligencia no humana jugará cada vez más un papel impórtate en todas las relaciones humanas de tipo cultural, laboral, militar y recreacional y; por el otro, que las naciones modernas y civilizadas tienen en consecuencia el deber moral de crear leyes que establezcan mecanismos de regulación y equilibrio entre la inteligencia artificial y la persona humana, como condición de posibilidad para que su uso generalizado no devenga en una distopia al estilo de lo plantado en su momento por algunas narrativas de ciencia ficción, en el cine y la literatura.

Palabras clave: inteligencia artificial; futuro inteligible; telemática; COVID-19; acción humana. 


\title{
Artificial Intelligence: An Intelligible Future
}

\begin{abstract}
As an editorial, this short essay aimed to reflect on the present and future of artificial intelligence, in the context of the pandemic of the new coronavirus. It is based on the hypothesis that observes in artificial intelligence a factor of the first order that has accelerated the technological $\mathrm{s}$ processes, which in turn drive continuous improvements in all fields of human action. However, despite its many benefits, it is concluded, on the one hand, that this form of non-human intelligence will increasingly play an important role in all cultural, labour, military and recreational human relations and; on the other hand, that modern and civilized nations therefore have a moral duty to create l eyes that establish mechanisms of regulation and balance between artificial intelligence and human condition, as a condition of possibility so that its widespread use does not become a distinction in the style of what was planted at the time by some sci-fi narratives, in film and literature.
\end{abstract}

Keywords: artificial intelligence; intelligible future; telematics; COVID-19; human action.

La pandemia COVID-19 que inicia en marzo del año 2020 y que continua a principios del 2021 sumergió al mundo en una de sus peores crisis políticas y económicas a lo largo de su historia (Villasmil, 2020a; Villasmil, 2020b). Hoy seguimos padeciendo los enormes inconvenientes que el virus produce y reproduce en su decurso; entre ellos, una especie de acuartelamiento que algunas personas asumen por temor y, otras, por obligación. Pero metafóricamente hablando donde unos ven oscuridad otros ven luz y en este sentido la pandemia ha obligado a un grueso número de empresas y trabajadores el tener que buscar una manera alternativa para seguir produciendo y generando bienes y servicios. Este tipo de práctica laboral en la actualidad se conoce como trabajo telemático y, muy seguramente, va a revolucionar las relaciones laborales en un futuro muy próximo.

Las innovaciones en este tipo de práctica telemática han acelerado un proceso tecnológico, que desde hace tiempo viene aflorando mejoras continuas en todos los campos de la acción humana; no referimos a la inteligencia artificial (Villasmil, 2021). En este sentido, esta forma de inteligencia es entendida por investigadores como Brito et al., (2019) como:

(...) un tipo particular de inteligencia tecnológica que, aunque tiene su punto de inicio en las personas, que es su artífice y causa primaria, puede funcionar con independencia y autonomía frente a la misma, llegando incluso a superar en muchos aspectos las capacidades cognitivas y procedimentales de la humanidad (Brito et al., 2019: 261). 
La creación de la inteligencia artificial ha sido planteada no solo por documentales sino por películas que revelan un futuro incierto pero que hoy ha llegado con sus aciertos y desaciertos. Desde los escritos de Julio Verne, hasta películas como el Exterminador ${ }^{2}$ y "Her ${ }^{3}$ " muestran un mundo donde esta forma de inteligencia no humana juega un papel predominante en la vida cotidiana de los seres humanos. Hoy gracias a los avances científicos en materia de informática se pueden realizar compras por internet de forma automática gracias a diferentes tipos de software creados para tal fin; igualmente, algunas empresas cuentan con robots que aminoran el esfuerzo humano y aceleran la cadena de producción. Un ejemplo claro se puede observar en las industrias automovilísticas donde maquinas preconfiguradas realizan trabajos cotidianamente asignados a seres humanos, haciendo que los vehículos se produzcan a gran escala, con menos esfuerzo y a menor costos para la empresa que cuenta con dicha tecnología.

Por otro lado, la inteligencia artificial también puede conducir a algunas personas hacia un mundo diferente donde el ensimismamiento es más importante que el contacto con la realidad. Un ejemplo que cotidianamente nos rodea es cuando observamos a jóvenes adictos a juegos interactivos o, simplemente, que pasan el día compartiendo con simuladores de una realidad paralela y, todo esto, sin tomar en consideración los niveles de violencia y destrucción simbólica que pueden generan algunos de esos juegos. Sin embargo, no debemos juzgar como malo el progreso tecnológico y científico pues el mismo será, o no, de utilidad, en función de los intereses de quienes los creen, modifiquen y controlen.

Cuando estamos frente a un procesador de información ya sea el teléfono inteligente o el computador debemos tener claro que podemos o no autorizar a los llamados Cookies al momento de acceder a ciertas aplicaciones pues estas inteligencias artificiales consolidadas en software están diseñadas para atraparnos; es decir, bombardeándonos constantemente con publicidad que nosotros mismos autorizamos al darle clic a aceptar; e inclusive podemos ser víctimas de robo de identidad y apropiación de datos por parte de piratas cibernéticos que crean programas inteligentes para despojarnos de nuestros bienes materiales. No obstante, no podemos agobiarnos por el progreso de la Inteligencia Artificial pues como ya hemos dicho más son los beneficios que los tropiezos. Hoy podemos mediante una aplicación disponible en la web visitar: Museos Virtuales, ver películas desde nuestros hogares y escuchar música sugeridas por nosotros mismos en anteriores

2 The Terminator. Película de ciencia Ficción protagonizada por Arnol Schwarzenegger y Linda Hamilton (1984) donde se muestra como Skynet una inteligencia artificial lidera un ejército de máquinas para exterminar a la humanidad.

3 Película de drama romántica producida en el año 2013 y protagonizada por Joaquín Phoenix donde el protagonista desarrolla una relación amorosa con Samanta quien resulta ser una asistente virtual con base a inteligencia artificial. 
oportunidades pues plataformas como YouTube, Netflix o AMAZON Prime, entre otras, facilitan el desarrollo de acceso a la información mediante algoritmos predeterminados que emulan y recrean nuestros gustos y preferencias al escuchar o ver en más de una oportunidad alguna música o video enmarcado en un ámbito temático específico (Vaganova, 2019; Vaganova et al., 2019).

Los países que no cumplan con los requerimientos y las condiciones materiales para incorporar dichas inteligencias artificiales como el internet $5 \mathrm{G}$ y empresas de reproducción de bienes robóticos, entre otras, quedaran relegados y a la intemperie al tener que depender de la producción tecnológica que de los países desarrollados provengan. Ya en Europa, se están haciendo ensayos con coches autónomos electritos e híbridos que te llevan de un sitio a otro sin necesidad de tocar el volante. En Japón, existen robot que ayudan con la limpieza y el mantenimiento del hogar entre otros logros asociados a la biotecnología.

De igual modo, conviene señalar que la inteligencia artificial también puede ser utilizada para otros fines como los de facilitar la obtención de ingresos financieros utilizando Máquinas para Minar Bitcoin y Criptomonedas en la bolsa de valores, y que, en algunos casos, pueden ser utilizadas para el blanqueo de capitales provenientes de corrupción y narcotráfico. También se puede utilizar la inteligencia artificial para desarrollar actividades destructivas como la conducción de drones para destruir objetivos militares, así como para el desarrollo de una carrera armamentística a nivel mundial. En este sentido, el deber de las naciones civilizadas es el de crear Leyes que establezcan mecanismos de regulación y equilibrio entre la inteligencia artificial y lo eminentemente humano para que esas películas apocalípticas como el Exterminador y Transcenderce no pasen de la ficción a la realidad (Arbeláez-Campillo y Villasmil, 2020).

\section{Referencias Bibliográficas}

ARBELÁEZ-CAMPILLO, Diego F; VILLASMIL ESPINOZA, Jorge J. 2020. "Escenarios Prospectivos de un Nuevo Orden Internacional que se Vislumbra Luego de la Pandemia COVID-19" En: www.doi. org/10.36390/telos223.02. Fecha de consulta: 12/02/2021.

BRITO PAREDES, Patrio; VILLAVICENCIO AGUILAR, Carmita; SÁNCHEZ SACA, Pamela. 2019. "Reflexiones sobre posibles conflictos entre la inteligenciaartificialyelfuturodelasociedad"En:RevistadelaUniversidad del Zulia. Disponible en línea. En: https://produccioncientificaluz. org/index.php/rluz/article/view/3080o/31842. Fecha de consulta: 12/02/2021. 
VAGANOVA, Olga I. 2019. "Formation of competence in the possession of modern educational technologies at a university" En: Amazonia Investiga. Disponible en línea. En: https://amazoniainvestiga.info/index.php/ amazonia/article/view/851/792. Fecha de consulta: 12/02/2021.

VAGANOVA, Olga I; SMIRNOVA, Zhanna V; GRUZDEVA, Marina L; CHAYKINA, Zhanna V; ILYASHENKO, Lyubov I. 2019. "Development of training content for master students in course «mechatronics and robotics» at the University" En: Amazonia Investiga. Disponible en línea. En: https://amazoniainvestiga.info/index.php/amazonia/article/ view/821/770. Fecha de consulta: 12/02/2021.

VILLASMIL ESPINOZA, Jorge. 2020a. "La fragilidad de las civilizaciones humanas" En: Cuestiones Políticas. Disponible en línea. En: https://doi. org/10.46398/cuestpol.3764.00. Fecha de consulta: 12/02/2021.

VILLASMIL ESPINOZA, Jorge. 2020b. ¿“Nos depara el futuro próximo el advenimiento de un nuevo orden mundial? En: Cuestiones Políticas. Disponible en línea. En: https://doi.org/10.46398/cuestpol.3865.00. Fecha de consulta: 12/02/2021.

VILLASMIL ESPINOZA, Jorge. 2021. "Implicaciones de la inteligencia artificial para la humanidad” En: Revista de la Universidad del Zulia. Disponible en línea. En: https://produccioncientificaluz.org/index.php/rluz/ article/view/34837/36778. Fecha de consulta: 12/02/2021. 

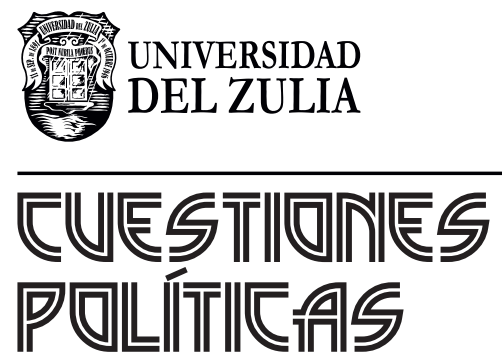

Vol.39 No 68

Esta revista fue editada en formato digital y publicada en enero de 2021, por el Fondo Editorial Serbiluz, Universidad del Zulia. Maracaibo-Venezuela 